\title{
Study on Surface Grouting Reinforcement Effect of Small Clear Distance Tunnel in Soil-rock Composite Stratum
}

\author{
PENG Lu-qiang ${ }^{1}$, CHEN Shi-hai ${ }^{1,2}$ \\ ( ${ }^{1 . C o l l e g e ~ o f ~ C i v i l ~ E n g i n e e r i n g, ~ H u a q i a o ~ U n i v e r s i t y, ~ X i a m e n, ~ 361021, ~ C h i n a ; ~}$ \\ 2. Fujian Research Center for Tunneling and Urban Underground Space Engineering, Huaqiao University, Xiamen 361021, China)
}

\begin{abstract}
Based on the Yingxiongshan tunnel project in Jinan, a numerical calculation model of tunnel excavation considering the surface grouting reinforcement effect of soil-rock composite stratum is established, and the effects of elastic modulus and grouting width of grouting reinforcement zone on tunnel stability are studied. and the research results are applied to the supporting project to verify the rationality of the numerical calculation results. The results show that grouting reinforcement can effectively control the deformation of surrounding rock and supporting structure, and the absolute value of surface settlement is negatively correlated with grouting width and elastic modulus. The surface settlement value is not sensitive to the change of the width of grouting reinforcement zone, but is sensitive to the change of elastic modulus.
\end{abstract}

\section{Introduction}

When a tunnel passes through soft soil layer or soft rock stratum, this will greatly aggravate the construction difficulty and affect the construction schedule, especially large section and small clear distance tunnels are prone to collapse during the construction due to their own characteristics ${ }^{[1]}$. Therefore, it is necessary to take certain pre-reinforcement measures according to the deformation mechanism of tunnels. The surface pre-grouting reinforcement measure is taken in many projects, as it can change the mechanical properties of front rock and soil mass, strengthen its deformation resistance, and reduce the possibility of excavation-induced collapse and loosening of rock and soil mass.

Many scholars have studied the surface grouting. When it comes to the grouting reinforcement process, Liu S J ${ }^{[2]}$, Zhang X F ${ }^{[3]}$, Wei C L ${ }^{[4]}$ and Wang $\mathrm{S}^{[5]}$ et al. adopted the sleeve valve tube surface grouting reinforcement process for intensely weathered granite and strongly permeable sand and gravel stratum, and the results showed that the sleeve valve grouting technology can effectively control the deformation of surrounding rocks. In terms of grouting materials, Yang $\mathrm{X} \mathrm{H}^{[6]} \mathrm{et} \mathrm{al}$. studied cement-water glass double-liquid grouting parameters. Zhang $\mathrm{J}^{[7]}$ et al. comparatively analyzed the single-liquid and double-liquid grouting reinforcement effects. Lai $\mathrm{H} \mathrm{P}^{\left[{ }^{8]}\right.}$ et al. analyzed the treatment effects of single-liquid grouting and double-liquid grouting. The abovementioned studies are of great significance for improving the surface grouting reinforcement technology.
However, the improving effect of grouting reinforcement on the mechanical properties of rock and soil mass has been rarely considered. Given this, the influences of elasticity modulus and grouting reinforcement width in the grouting reinforcement zone on the tunnel stability were analyzed via numerical simulation.

\section{Project Profile}

The full length of two-way six-lane Yingxiongshan Tunnel is about $1.47 \mathrm{~km}$. The maximum clear distance of this tunnel is $25 \mathrm{~m}$, and the clear distance is the minimum at the southern and northern portals, being $5 \mathrm{~m}$ and $7 \mathrm{~m}$, respectively. The minimum burial depth appears at the southern and northern portals, too, being about 3-4 m. Cross-section view of the tunnel is shown in Figure 1.

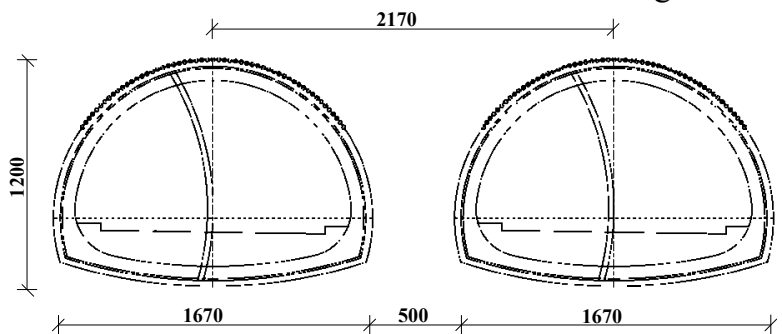

Figure 1: Cross-section of the Tunnel

The tunnel surrounding rocks, whose grade is V, are loose and broken, there are mostly quaternary soil layer, macadam, etc. at the roof, the tunnel body main passes through cohesive soil, macadam, cementing gravel, and limestone, the surrounding rocks have no self-stabilizing ability, the geological conditions of left and right lines are not greatly different, and the vertical sectional graph

Corresponding author: Shihai Chen (1964-), male, professor, doctor, mainly occupied in the studies of geotechnical engineering.

E-mail: cshblast@163.com. 
of right-line portal is shown in Figure 2.

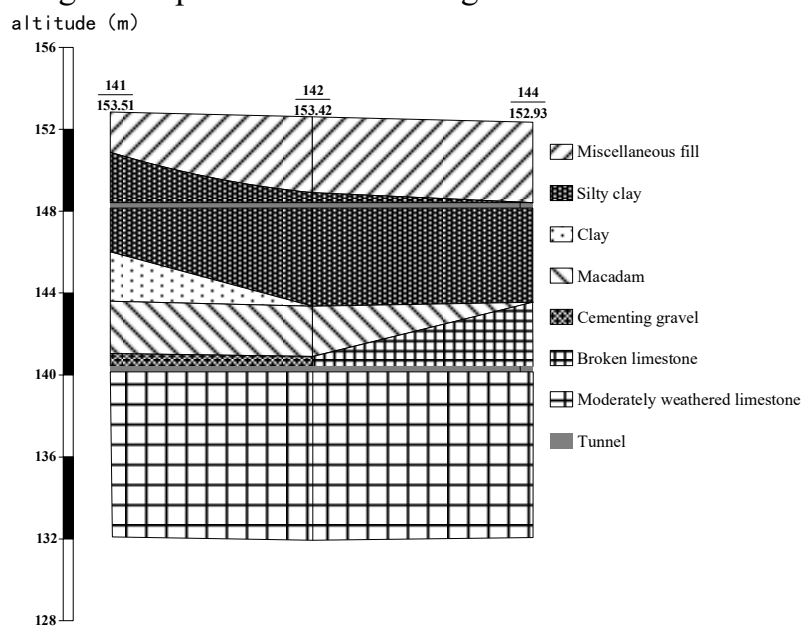

Figure 2: Vertical Sectional Graph of Right-Line Portal

\section{Calculation Model and Parameters}

The southern portal section of this tunnel was selected to establish a 3D numerical model considering geological conditions via preprocessing software, in which different strata were distinguished using different colors. As the scope of influence of tunnel excavation is 3-5 times of tunnel portal diameter ${ }^{[8]}$, the model length was $197 \mathrm{~m}$ and $69 \mathrm{~m}$ in the direction of axis $\mathrm{X}$ and axis $\mathrm{Y}$, respectively, and the tunnel length in the axial direction was $50 \mathrm{~m}$. The displacement boundary conditions were as follows: A free boundary existed at the model top, without any constraint; at the bottom, the constraints were applied in three directions; the sides of the model were applied with constraints in normal direction. In the whole model, the surface load was not considered, but only the self-weight stress of rock and soil mass was considered and set as $10 \mathrm{~m} / \mathrm{s}^{2}$, and the calculation model is shown in Figure 3.

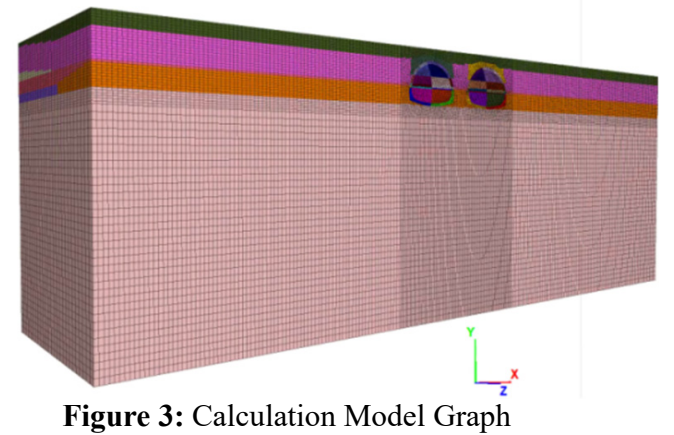

The tunnel excavation process was simulated using the Mohr-Coulomb constitutive model, where the values of $c$ (soil cohesion), $\varphi$ (internal friction angle) and $\rho$ (soil density) can be taken by reference to practical engineering geological investigation report. Poisson's ratio $\mu$ is acquired according to related empirical data. In general, Young's modulus cannot be directly obtained, but acquired by two calculation methods: For soil layer, it is 3-5 times of modulus of soil compressibility; for rock stratum, it can be calculated according to the shear wave velocity measured in the rock-soil wave velocity test of drill hole, as shown in Equation (1) and (2), respectively, and the concrete soil parameters are listed in Table $1^{[9]}$.

$$
\begin{aligned}
& E=2(1+\mu) \mathrm{G}_{0} \\
& G_{0}=\rho V_{S}^{2}
\end{aligned}
$$

Table 1: Soil Parameters

\begin{tabular}{cccccc}
\hline Rock-soil & $\gamma\left(\mathrm{kN} / \mathrm{m}^{3}\right)$ & $E(\mathrm{MPa})$ & $\mu$ & $c(\mathrm{kPa})$ & $\varphi\left({ }^{\circ}\right)$ \\
\hline Miscellaneous & 19.5 & 30 & 0.31 & 5 & 12 \\
$\quad$ fill & 19.5 & 42 & 0.37 & 27.3 & 17.8 \\
Silty clay & 19.2 & 64 & 0.36 & 40 & 20.5 \\
$\quad$ Clay & 19 & 648 & 0.35 & 5 & 35 \\
Macadam & 21 & 943 & 0.33 & 30 & 40 \\
$\begin{array}{c}\text { Cementing } \\
\text { gravel }\end{array}$ & 21.5 & 4700 & 0.31 & 300 & 33 \\
$\begin{array}{c}\text { Broken } \\
\text { limestone }\end{array}$ & 25.5 & & & & \\
$\begin{array}{c}\text { Moderately } \\
\text { weathered } \\
\text { limestone }\end{array}$ & 26.5 & 5000 & 0.26 & 700 & 39 \\
\hline Soil & & & & & \\
\hline
\end{tabular}

Soil mass and secondary lining were simulated using ZONE units; the advanced support was simulated by increasing the parameter values of surrounding rock in the reinforcement zone; initial support, mid-partition wall and inverted arch were simulated through shell units; when initial support, mid-partition wall and inverted arch were considered through the method of equal effects during the simulation, the elasticity modulus of steel arch was converted to concrete according to the equality principle of compressive stiffness [10], the concrete convert formula is seen in Equation 3, and the structural parameters are seen in Table 2. In the numerical simulation, the grouting reinforcement zone was simulated using ZONE units, the grouting effect was realized by increasing the parameter values (elasticity modulus and cohesion) of surrounding rock within the grouting scope, and under normal circumstances, the elasticity modulus could be elevated to 1.25 and 1.56 times of the original value, while the cohesion to 10 to 55 times of the original cohesion ${ }^{[10]}$. The parameters of supporting structure are presented in Table 2 .

$\mathrm{E}=E_{0}+\frac{S_{g} \times E_{g}}{S_{c}}$

Where $\mathrm{E}$ is the elasticity modulus of concrete after the conversion; $\mathrm{E}_{0}$ is the elasticity modulus of original shotcrete; $\mathrm{S}_{\mathrm{g}}$ is the sectional area of steel arch; $\mathrm{E}_{\mathrm{g}}$ is the elasticity modulus of steel; $\mathrm{S}_{\mathrm{c}}$ is the sectional area of concrete.

Table 2: Parameters of Supporting Structure

\begin{tabular}{cccc}
\hline Supporting structure & $\gamma\left(\mathrm{kN} / \mathrm{m}^{3}\right)$ & $E(\mathrm{MPa})$ & $\mu$ \\
\hline Secondary lining structure & 24 & 32.5 & 0.2 \\
Initial supporting structure & 25 & 28.6 & 0.2 \\
Temporary supporting structure & 25 & 28.6 & 0.2 \\
Advanced support & 19.2 & 0.013 & 0.37 \\
\hline
\end{tabular}

\section{Analysis of Numerical Simulation Results}

The width of grouting reinforcement was set as $21 \mathrm{~m}$, the elasticity modulus in the grouting reinforcement zone as $80 \mathrm{MPa}$, and the cohesion as $70 \mathrm{KPa}$, in an effort to analyze the deformation of surrounding rock and supporting structure before and after the grouting reinforcement. 


\subsection{Peripheral displacement analysis}

The vertical displacement nephograms of surrounding rock before and after the reinforcement were extracted, as shown in Figure 4. It could be seen that the scope of influence of tunnel excavation on the surrounding rock above the vault without reinforcement measure was obviously smaller than that with the reinforcement measure taken. No matter whether the surface grouting was done or not, the vertical displacement of surrounding rock nearby the tunnel spandrel was always large. Uplifting phenomenon occurred at the inverted arch of tunnel, but the uplift values before and after the grouting reinforcement were not different greatly. In general, the surrounding rock experiencing the grouting reinforcement was smaller than that without the grouting reinforcement, indicating that the strength of surrounding rock can be enhanced by the grouting reinforcement.

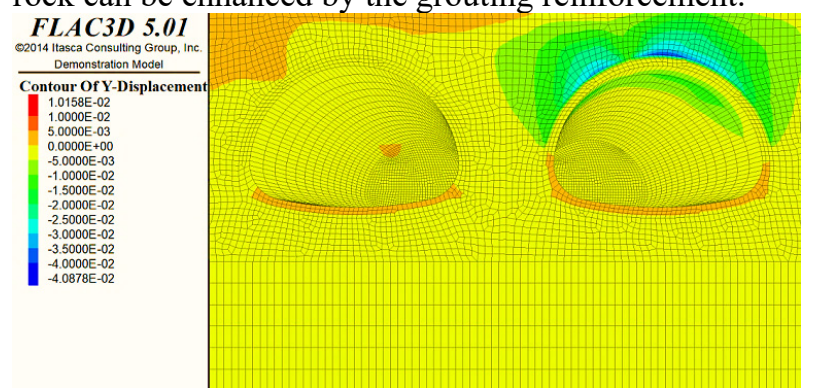

(a) Before grouting reinforcement

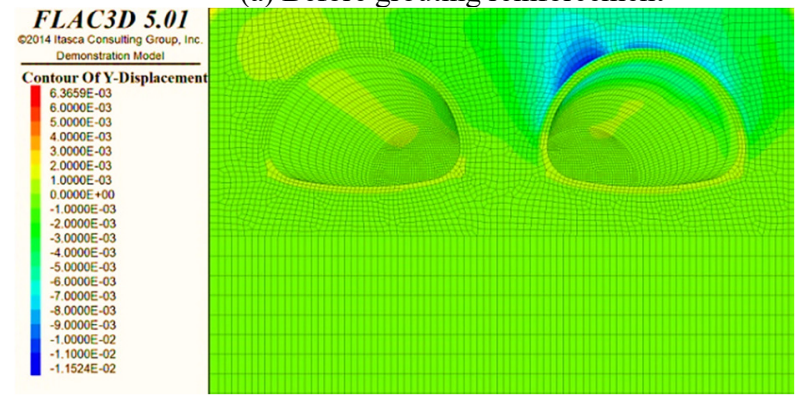

(b) After grouting reinforcement

Figure 4: Vertical Displacement Nephograms of Surrounding Rock

\subsection{Displacement and force analysis of supporting structure}

In order to explore the stress and displacement of supporting structure before and after the grouting reinforcement, the vertical displacement nephograms of initial support before and after the grouting reinforcement were extracted as shown in Figure 5, so were the maximum and minimum principal stress nephograms (Figure 6) of initial support before and after the grouting reinforcement.

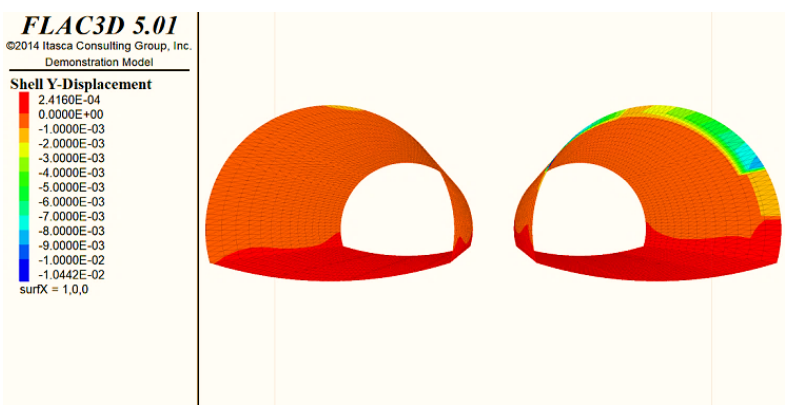

(a) Before grouting reinforcement
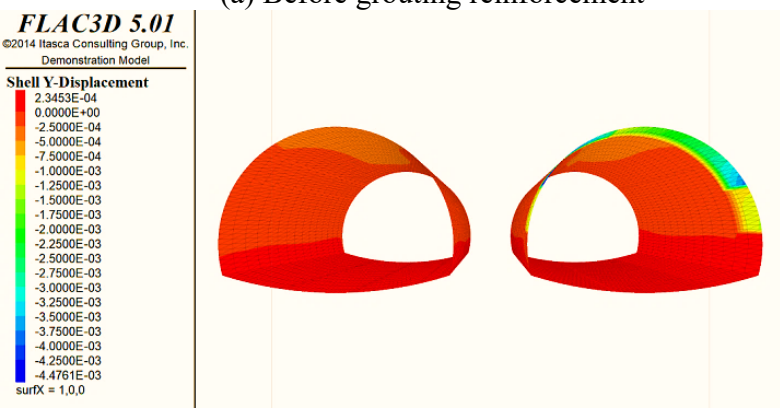

(b) After grouting reinforcement

Figure 5: Vertical Displacement Nephograms of Initial Support

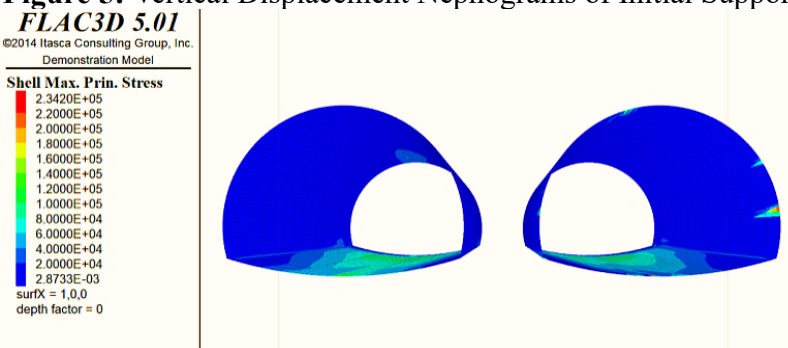

(a) Before grouting reinforcement

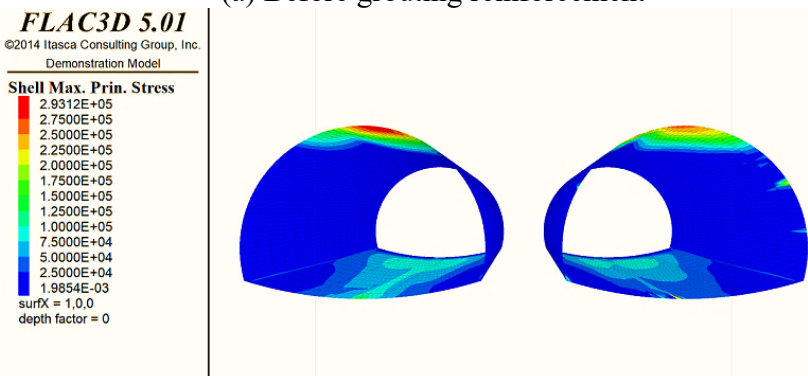

(b) After grouting reinforcement

Figure 6: Maximum Principal Stress Nephograms of Initial Support

As shown in Figure 5, the vertical displacement of initial support was large within the range from vault to hance, in which the settlement deformation played a dominant role. The uplift deformation appeared nearby the arch bottom, and the uplift value was generally small. The maximum settlement value of initial support was $10.4 \mathrm{~mm}$ and $4.5 \mathrm{~mm}$ before and after the grouting reinforcement, respectively, manifesting that the deformation of supporting structure can be effectively controlled by the grouting reinforcement. As shown in Figure 6, the maximum principal stress value at the vault was large before the grouting reinforcement, but that after the grouting reinforcement was obviously reduced, indicating a remarkable grouting reinforcement effect. After the grouting reinforcement, the maximum principal stress was decreased by about $20 \%$. As a whole, the maximum principal stress of initial support was kept within a safety range. 


\section{Influencing Factor Analysis of Settlement Deformation}

With the ground surface settlement taken as an evaluation index, the influences of elasticity modulus and grouting width in the grouting reinforcement zone on the surface settlement deformation were studied. The grouting width was selected as $17,19,21,23,25$ and $0 \mathrm{~m}$ (no grouting), and the elasticity modulus of grouting reinforcement zone was taken as 60 (no grouting), 80, 120,160 and $200 \mathrm{MPa}$. As only the influence of the change in grouting parameters on the stability of surrounding rock will be discussed, only the heading hole (right hole) was simulated this time.

\subsection{Influence of grouting reinforcement width}

In the grouting zone, the elasticity modulus of surrounding rock was set as $200 \mathrm{MPa}$, the cohesion as $0.14 \mathrm{MPa}$, and the grouting width as 17, 19, 21, 23, 25 and $0 \mathrm{~m}$ (no grouting), followed by a numerical simulation under the six different working conditions. The influence of grouting width on the surface settlement is depicted as shown in Figure 7, and the corresponding maximum surface settlement values are presented in Figure 8.

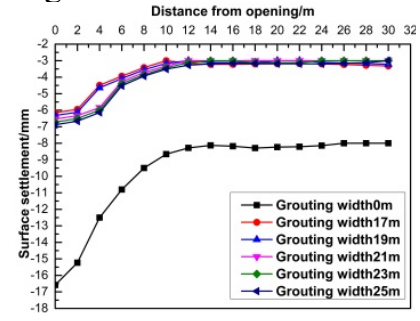

Figure 7: Influence of Grouting Reinforcement Width on Surface Settlement

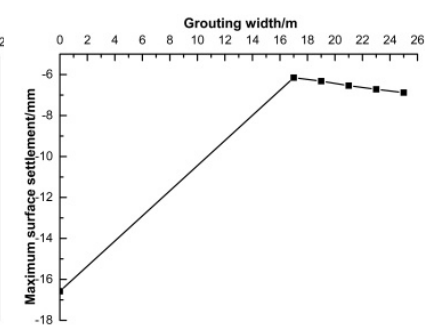

Figure 8: Influence of Grouting Reinforcement Width on Maximum Surface Settlement
It could be observed from Figure 7 and Figure 8 that the surface settlement was significantly affected by the change in grouting width. When grouting was not implemented, the maximum surface settlement value was $16.58 \mathrm{~mm}$, but after the grouting, the maximum surface settlement was just $37 \%-41 \%$ of the former. The absolute value of surface settlement was negatively correlated with the grouting width: With the increase in grouting width, the surface settlement was gradually reduced, and finally tended to be steady, indicating that the surface grouting can effectively reduce the surface settlement, but the surface settlement was not obviously inhibited by the change in grouting width. Within the $0-10 \mathrm{~m}$ range from the tunnel portal, no matter whether surface grouting was carried out, the change rate of surface settlement with the increase in the distance from the portal was large, but within the $10-30 \mathrm{~m}$ range, the surface settlement changed a little with the increase in the distance from the portal, this was because: The overall strength of surrounding rock nearby the tunnel portal is low due to its high weathering degree, and as a result, it is greatly disturbed by the tunnel excavation, thus leading to a large deformation of surrounding rock.

\subsection{Influence of elasticity modulus in grouting reinforcement zone}

In the grouting reinforcement zone, the grouting reinforcement width was set as $21 \mathrm{~m}$, the cohesion as $0.14 \mathrm{MPa}$, and the elasticity modulus as 60 (no grouting), $80,120,160$ and $200 \mathrm{MPa}$, and then a numerical simulation was done under the five different working conditions. The influence of elasticity modulus in the grouting reinforcement zone on the surface settlement is shown in Figure 9, and the corresponding maximum surface settlement values are displayed in Figure 10.

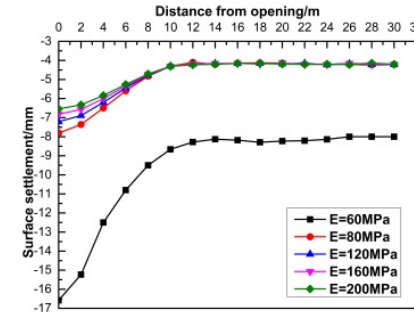

Figure 9: Influence of Elasticity Modulus on Surface Settlement

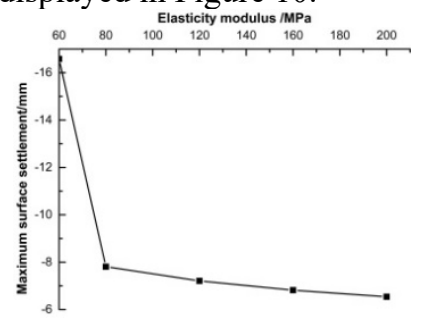

Figure 10: Influence of Elasticity Modulus on Maximum Surface Settlement
As shown in Figure 9 and 10, the maximum surface settlement value was $16.58 \mathrm{~mm}$ before the grouting, but that after the grouting was $39-47 \%$ of the former. A negative correlation appeared to exist between the absolute value of surface settlement and elasticity modulus of grouting reinforcement zone: The surface settlement was under a gradual decline with the increase in elasticity modulus, and the maximum surface settlement declined from $7.81 \mathrm{~mm}$ to $6.54 \mathrm{~mm}$ as the elasticity modulus of grouting reinforcement zone was increased from $80 \mathrm{MPa}$ to $200 \mathrm{MPa}$, manifesting that the strength of surrounding rock in the tunnel vault zone can be improved by increasing the elasticity modulus in the grouting reinforcement zone. As the surface was turned away from the tunnel portal, the surface settlement was reduced, and the surface presented an uplifting trend. To figure out why, as the grouting construction proceeds, the grout will fill the soil layer, a propelling pressure is then generated, which will cause the surface uplift, and moreover, the surface settlement will result from the release of propelling pressure. Meanwhile, the surface settlement is also the result of excavation disturbance, and the surface uplift or settlement is a comprehensive reflection in the grouting construction process ${ }^{[12]}$.

\section{Engineering Example Verification}

According to the above study results and in a comprehensive consideration of economic factors, the parameters of surface grouting reinforcement zone in the portal section of Yingxiongshan Tunnel are seen in Table 3 , the corresponding maximum surface settlement was $6.34 \mathrm{~mm}$ and the monitoring point at the construction site was DBC2-1.

Table 3: Parameters of Surface Grouting Reinforcement Zone

\begin{tabular}{cccc}
\hline Supporting structure & $E(\mathrm{MPa})$ & $W(\mathrm{~m})$ & $c(\mathrm{kPa})$ \\
\hline reinforcement zone & 120 & 17 & 70 \\
\hline
\end{tabular}

To reach the parameters of grouting reinforcement 
zone as seen in the above table, the double-liquid grouting process was selected, namely, two solutions-water glass and cement slurry-were alternately injected into the rock-soil mass to generate rapid reaction and produce calcium silicate gel and silica gel, which exerted a rapid setting effect. The water to cement ratio was $1: 1$, and the volume ratio of cement slurry to water glass was $3: 1$. The grouting pressure was initially set as $1 \mathrm{MPa}$. The diffusion radius of grouting was $0.9 \mathrm{~m}-1.2 \mathrm{~m}$, and the grouting parameters should be dynamically adjusted in the grouting construction process.

The change curve of surface settlement at monitoring point DBC2-1 is shown in Figure 11. It could be known that the final settlement at DBC2-1 was $7.67 \mathrm{~mm}$, being greater than $6.34 \mathrm{~mm}$ numerically calculated, and the main reason was that: The surrounding rock is monitored and measured after the tunnel excavation, so the deformation in the initial excavation phase cannot be acquired. In general, the error between numerically calculated data and measured data was very small, indicating that the numerical calculation is basically reasonable.

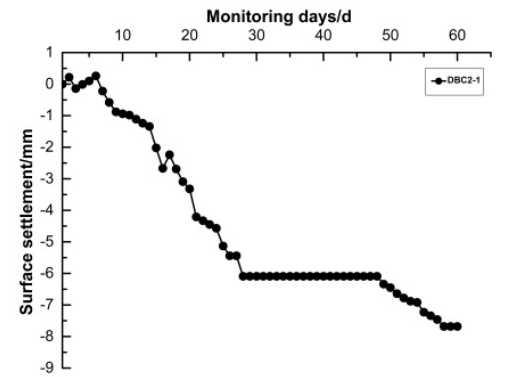

Figure 11: Curve Chart of Surface Settlement

\section{Conclusion}

(1) No matter whether the surface grouting is constructed, the peak vertical displacement of surrounding rock is distributed nearby the tunnel spandrel. The uplift phenomenon takes place at all inverted arches of the tunnel, but the uplift value is not much different before and after the surface grouting reinforcement. The grouting reinforcement effect is significant, as the vertical displacement of surrounding rock after the grouting reinforcement measure is taken is only $29 \%$ of that without grouting reinforcement, and the deformation value of surrounding rock is always within the control range of deformation after the grouting reinforcement.

(2) The peak vertical displacement of initial support appears within the range from vault to hance, in which the settlement deformation occurs. An uplift deformation is generated at the arch bottom, but the uplift deformation value is small. The maximum settlement value of initial support is $4.48 \mathrm{~mm}$ and $-1.04 \mathrm{~mm}$ before and after the grouting reinforcement, respectively, indicating that the grouting reinforcement can effectively control the deformation of supporting structure.

(3) The maximum principal stress value of initial support is $0.293 \mathrm{MPa}$ and $0.234 \mathrm{MPa}$ before and after the grouting reinforcement, respectively, meaning that the grouting reinforcement can effectively reduce the maximum principal stress of initial support

(4) The absolute value of surface settlement is negatively correlated with the grouting width and elasticity modulus, that is, the surface settlement of the tunnel is gradually reduced with the increase in the grouting width and elasticity modulus. The surface settlement is not sensitive to the change in the width of grouting reinforcement zone, but to the change in its elasticity modulus.

\section{Acknowledgments}

supported by National Natural Science Foundation of China (51974136)。

\section{References}

1. Yang Jianhua,Zhu Bin.Construction of long span and soft rock tunnel with numerical simulation[J].Journal of xi'an University of Science and Technology, 2011, 31( 3):287-292.

2. Liu Shijie,Liu Ze,Wu Jianhe,Zhong Youjiang.Ground surface grouting techniques for the railway tunnel in completely weathered granite stratum[J].Modern Technology,2019,56(6):181-186.

Tunnelling

3. Zhang Xiaopu,Zhou Guannan,Su Huayou.Surface Grouting reinforcement technique of sleeve valve pipe in the shallow-buried tunnel under complicated geological condition[J].Construction Technology, 2017 (S2):1049-1052.

4. Wei Chenliang,Wang Yuqing,Tang Gaohong.Case study on consolidation of water-rich cobble ground in nanning by means of soletanche grouting[J].Tunnel Construction,2014,34 (5):499-502.

5. Wang Sheng,Guo Jiaqi,Gao Baobin,et al.Experimental study and application of mix proportion of sleeve valve tube grouting[J].China Concrete and Cement Products,2018 (3):16-20.

6. Yang Xiaohua,Yu Yonghua.Application of cement-silicate double solution grouting in loess tunnel constructi on[J].China Journal of Highway and Transport,2004,17(2):68-72.

7. Zhang Jian,Li Shucai,Li Zhaofeng,et al.Comparative study of reinforcement patterns between single- and double- fluid grouting in fully-weathered granite[J]. Journal of Central South University (Science Technology),2018,49(12):3051-3059.

8. Lai Hongpeng,Xie Yongli,Yang Xiaohua.Treatment effect analysis of shallowburied crushed surrounding rocks underground unsymmetrical pressure reinforced with surface pregrouting technology in highway tunnel[J].Chinese Journal of Rock Mechanics and Engineering,2008, 27( 11) : 2309-2315.

9. Chen Ping.Research on the rationality of the excavation method of small-distance tunnel[J]. 
Journal of Railway Engineering Society,2018,35(4): 65-69.

10. Li Mingguang.Deformation behavior of adjacent retaining walls in group excavation[D].Shanghai Jiao Tong University,2016.

11. Jiang Biao,Xiao Yan,Li Lingyi.Simulation analysis on construction methods of subsurface excavated subway tunnel with large span and super small
interval[J].Journal of Railway Science and Engineering,2011,8( 5) :46-50.

12. Sun Jie,Peng Luqiang. Rationality analysis of excavation method of large-section tunnel with small clear spacing in composite geological conditions[J]. Municipal Engineering Technology,2020,38(06): 161-165+170. 